\title{
Subjective Age Identity duRING the Transition to Adulthood: Psychological and Sociological PERSPECTIVES
}

\author{
Justin Allen Berg \\ Washington State University
}

\begin{abstract}
This review examines the literature on subjective age identity during the transition to adulthood. After a brief discussion of the concept of adult status, it presents psychological and sociological explanations of feeling like an adult. Psychology interprets this phenomenon to be a function of individualistic qualities, such as believing one self to be financially responsible or being able to make personal decisions without the help of others. Sociology focuses on the impact of taking on new social roles in particular social contexts, such as the workplace and school. Currently, some scholars argue that factors from both disciplines are interrelated. At the end of the review several theoretical and methodological suggestions are offered to improve future research in this area.
\end{abstract}

\section{Introduction}

Most social scientists consider age to be a social construct that generates collective and individual meaning (Logan, Ward, and Spitze 1992) and aging to be a dynamic social process within the life course (Riley, Foner, and Waring 1988). For example, societ-

Please direct all correspondence to the author at the Department of Sociology, Washington State University, Pullman, Washington 99164-4020. Tel: (509) 3354595. E-mail: justinb@mail.wsu.edu. The author would like to thank Monica Kirkpatrick Johnson and two anonymous reviewers for their helpful comments on an earlier version of this manuscript. 
ies designate specific ages in which members are legally allowed to engage in particular activities. In the US, a person may enter the armed forces at age 18 or begin drinking alcohol at age 21 . These ages identify socially-established points in the life course when an individual is believed to have sufficient life-experience to begin participating in various social events. Notwithstanding this organized agreement, many families may still regard the son or daughter to be "too young" to take part in certain social activities. At the same time, an individual who has not arrived at the designated chronological age may consider him or herself to be "old enough" to manage any activity. These are examples of an informal or subjective understanding of age. There is evidence that people often apply a "subjective age" perspective rather than estimating actual ages when interacting with others and when judging the self as they progress through the life course (Barak 1987; Kaufman and Elder 2002; Montepare 1991).

For over 50 years psychologists and sociologists have been investigating the factors that lead someone to construct a subjective age identity (e.g., see Blau 1956; Kastenbaum, Derbin, Sabatini, and Artt 1972). More recently the topic has been studied within the ages of transitioning to adulthood, approximately between 18 and 30 (e.g., see Arnett 1998; Shanahan, Porfeli, Mortimer, and Erickson 2005). This review examines the literature on subjective age identity during the transition to adulthood by asking two main questions: What are the current theoretical perspectives regarding this phenomenon and what can be done to improve research in this area? After brief discussions on the history of the concept of adult status and the study of subjective age identity, theoretical perspectives from psychology and sociology are presented. In conclusion, several suggestions are offered that may enhance future research regarding subjective age identity during the time when youth begin to view themselves as adults.

\section{Historical Change in Adult Status}

Throughout the $19^{\text {th }}$ century and into the early part of the $20^{\text {th }}$ century, the main social markers of adult status were obtaining 
some form of education, gaining stable employment, establishing an independent residence, marrying, and becoming a parent (Hogan 1981; Shanahan 2000b). This particular order of transitions was also considered the normative sequence of events, yet notably for males (Marini 1984a; Shanahan 2000b). Much of this perception was founded on the statistical regularity in the timing of individual life course transitions (Hogan 1978). Many people seemed to enter and exit specific social roles around the same age throughout their lives. This prompted the examination of age norms, which constitute a shared understanding of the appropriate or inappropriate age-timing of particular actions within the life course. Some researchers found significant evidence for age norms (Hogan 1978; Neugarten, Moore and Lowe 1965), while other researchers considered the phenomenon to be measured incorrectly and the evidence therefore limited in value (e.g., see Marini 1984b).

In either case, in the later half of the $20^{\text {th }}$ century life course transitioning changed (Arnett and Taber 1994; Mortimer 2000). The age at which people married for the first time, gained an educational degree, became parents, and began a career was different on a nationally demographic scale compared to previous decades, and the sequence of events no longer appeared to be so orderly, especially when more populations than the white majority were included in the research (Shanahan 2000a). In an explanation of these trends, Shanahan (2000a) describes the standardization and individualization of life course transitions. In many cases, the variation in age at the time of transitioning has decreased over time. In other words, due to the organization and institutionalization of society, the age-timing of particular events, such as graduating high school, has become standardized (Fussell and Frustenberg, Jr. 2005). Simultaneously, the variation in the sequencing of events has increased (Mouw 2005). Men often marry before completing a college degree and many women work before parenthood (Marini 1984a). This variability constitutes the individualization of the life course. Thus, while much of a young person's life is formally structured, youth show significant variation in their sequencing of traditional transitions. 
Nonetheless, individuals persist in believing that there are proper ages and sequences of life course events. Greene (1989) finds that adolescents approached their life course with expectations of certain events, specific timing of events, and the traditional normative perspective on the ordering of events. There is some evidence, however, that suggests that individuals who fail to follow these normative patterns experience mild negative sanctions compared to individuals who lived in the $19^{\text {th }}$ century. Settersten Jr. and Hagestad (1996) argue that people embrace cultural schedules, particularly for family transitions, yet they personally extend a low degree of social sanctioning on friends or family members who do not transition at the perceived appropriate time.

Due in large part to these demographic changes in combination with different cultural norms, the point at which a person acquires a self-perceived adult status is difficult to identify because the traditional markers and norms may not offer the same insight into an individual's perceptions of adulthood as they did in the past (Arnett 1998). Currently, this life course transition of feeling like an adult is recognized as a process that differs by many individual and social characteristics (Hogan and Astone 1986). Consequently, understanding peoples' subjective age identities with regard to adult status is analytically complex.

\section{The Study of Subjective Age Identity}

At least as early as the 1950 s, researchers began documenting differences between people's chronological age and their self-perceived age (e.g., see Blau 1956 and Zola 1962). Self-perceived age has become synonymous with subjective age identity, which refers to a person's individual and social perception of age (Settersten, Jr. and Mayer 1997). In 1972, Kastenbaum, Derbin, Sabatini, and Artt developed an influential pattern for studying subjective age identity, which they called personal age. They divided the topic into four main categories: look age ("I look as though I were about age ..."), feel age ("I feel as though I were about age ..."), do age ("I do most things as though I were about age ..."), and interests age ("My interests are mostly those of a person about age ..."). In their 
study, they found that, on average, the majority of people in all age groups recorded a difference between their personal age and their chronological age and the direction of the difference pointed to a more youthful personal perspective. Additionally, with an increase in chronological age, there was an increase in the divergence between actual age and personal age.

After this study, various other strategies were developed to further explore the measurement possibilities of capturing and explaining the discontinuity between subjective age and chronological age. Barak (1987) describes three: identity age (identifying with certain age groups, such as young, middle-aged, and old), cognitive age (a combination of identity age and the Kastenbaum et al. (1972) personal age and the use of age decades instead of raw age), and discrepancy age (the discrepancy between people's chronological age and their ideal age). In his study of New York women, he found that a lower subjective age was associated with a higher self-image and the women who had ideal ages that were closer to their actual ages were more positive about age in general. Montepare and Lachman (1989) discovered that teenagers held older subjective age identities, young adults did not have much disparity between feel age and actual age, and adults felt younger than their chronological age. Women in their study tended to link feel age with life satisfaction, while men did not. In another study, Montepare (1991) added some new categories: act age, desired age, and the age respondents' thought others believed them to be. He found that teenagers and young adults in their early twenties thought that they acted older than their age and were regarded by others as older than their age. The respondents' perceptions of other people assuming them to be older were related to their level of selfconfidence. In a more in-depth attempt to psychologically study and explain subjective age identity, Hubley and Hultsch (1994; 1996) found that feeling younger was associated with an internal locus of control, or, in other words, feeling in control of one's personal affairs, and with the personality traits of extraversion and being open to new experiences.

In addition to these descriptive and psychological studies, scholars conducted sociological research on subjective age iden- 
tity. Barnes-Farrell and Piotrowski (1989) studied feel age of persons employed in a manufacturing organization. They found that persons below 30 felt older and those over 30 felt younger than their chronological age. They speculated that the particular place of employment and work in general likely impacted perceptions of age. Considering the influence of social institutions, Goldsmith and Heiens (1992) suggested that look age and feel age are possibly related because of the media's cultural promotion to purchase cosmetic products that will induce a youthful appearance and presumably make a person feel better. They also found in their study that persons in their 30s expressed the most variability in feel age. They proposed that persons in their 30s experience more life course transitions (e.g., marriages, births, divorces) than other age groups, leading some people to feel older and others to feel younger. Kaufman and Elder $(2002 ; 2003)$ found evidence that life course transitions impact the subjective age identities of older adults. In their gerontological studies, they discovered that the grandparents who enjoyed being grandparents, felt younger and healthier and desired to live longer than those who did not enjoy the grandparent role. Similarly, in reference to age norms, the grandparents who entered grandparenthood earlier than the age they thought was appropriate felt older than those who had entered it at a normative time. There was also a small group of people who were close to the age of 65 that wanted to be older. They concluded that this group of people was probably looking forward to the new social role of retiree.

Both the psychological and sociological research establishes some basic conclusions about subjective age identity. Persons in adolescence and young adulthood tend to view themselves as older than their chronological age, while adults and the elderly tend to view themselves as younger than their chronological age. Individual qualities as well as social settings, such as workplace and family contexts, and social roles appear to influence a person's self-perceived age. Many scholars from both disciplines offer theoretical explanations of feeling like an adult in the time of transitioning to adulthood. 


\section{Differences in Theoretical Perspectives}

In the study of subjective age identity during the transition to adulthood, some researchers argue that psychological factors are the most salient when explaining the reasons behind feeling like an adult (e.g., see Arnett 1998). Other social scientists study and promote the significance of social context, like the workplace, and the impact of social roles (e.g., see Benson and Furstenberg, Jr. 2004). More recently, there is a third perspective, which argues that psychological and sociological factors are interrelated in producing feelings of being an adult (e.g., see Shanahan, Porfeli, Mortimer, and Erickson 2005).

\section{Psychology}

Arnett (1998) is likely the strongest proponent of investigating subjective age identity during the transition to adulthood from a psychological perspective. He (2000; 2003; Arnett and Taber 1994) argues that, in the contemporary West, the transition to adulthood is delayed for numerous youth because of the cultural ideologies of independence and individualism. Adulthood, he contends, is no longer defined by social events, such as marriage, but rather is dependent on the individual's psychological state. If the individual is cognitively self-sufficient, emotionally self-reliant and behaviorally self-controlled, then it is likely that the person will think of him or her self as an adult and be perceived by others as an adult (cf. Shanahan, Porfeli, Mortimer, and Erickson 2005). Yet, reaching this state requires time. It is a process. For American youth, Arnett (2000) theorizes that the period between leaving adolescence and entering adulthood is adequately lengthy to require a separate designation within the life-span. He calls it "emerging adulthood".

In one study using a convenience sample, Arnett (1998) asked individuals aged between 21 and 28 what items they thought "must be achieved before a person can be considered an adult" (303). The top three responses were: "accept responsibility for the consequences of your actions"; "decide on personal beliefs and values independently of parents or other influences"; and "financially 
independent from parents." Traditional social markers, such as married, employed full-time, have at least one child, and finished education, all ranked lower than 30 out of 38 choices. He interpreted these findings as indicating that Americans in their teens and early twenties emphasize individualistic qualities of character in their conception of adulthood rather than socially recognized roles or transitions. Greene, Wheatley, and Aldava (1992) found similar results in their study. The three adult characteristics most cited by the 17 to 21 year old high school and college students were financial independence, autonomous decision making and responsibility. In a qualitative study, Tilton-Weaver, Vitunski and Galambos (2001) discovered that $6^{\text {th }}$ and $9^{\text {th }}$ graders described the meaning of "maturity" and "grown-up" in individualistic terms (e.g., psychosocial and behavioral maturity; power; acting responsibly and physical development). There was no mention of life course transitions, such as marrying or becoming a parent. Arnett (2003) conducted another study with a convenience sample of African Americans, Latinos and Asian Americans, aged 18 to 29. He learned that the perceptions of these minorities differed in some respects to their white counterparts, but not in the relevance of individualistic qualities of adulthood. The main perceptions included accepting personal responsibility, independently establishing personal beliefs and values, gaining financial independence and developing an equal relationship with parents. If youth feel that they meet these individual qualities, they are likely to consider themselves to be an adult. Figure 1 offers a visual illustration of this psychological perspective.

It is important to note, however, that these empirical findings identify individual conceptions of the qualities of an adult in the abstract, that is, a hypothetical person who reaches adulthood. They are not the respondent's conceptions of his or her own adult status. The results are significant in the sense that the perceptions a person holds regarding the meaning of adulthood are likely to correlate with the person's own feelings of being an adult. If the person believes that certain individual qualities are important to have to be an adult, and, at the same time, believes that he or she possesses those qualities, then it is most likely he or she will perceive him or 


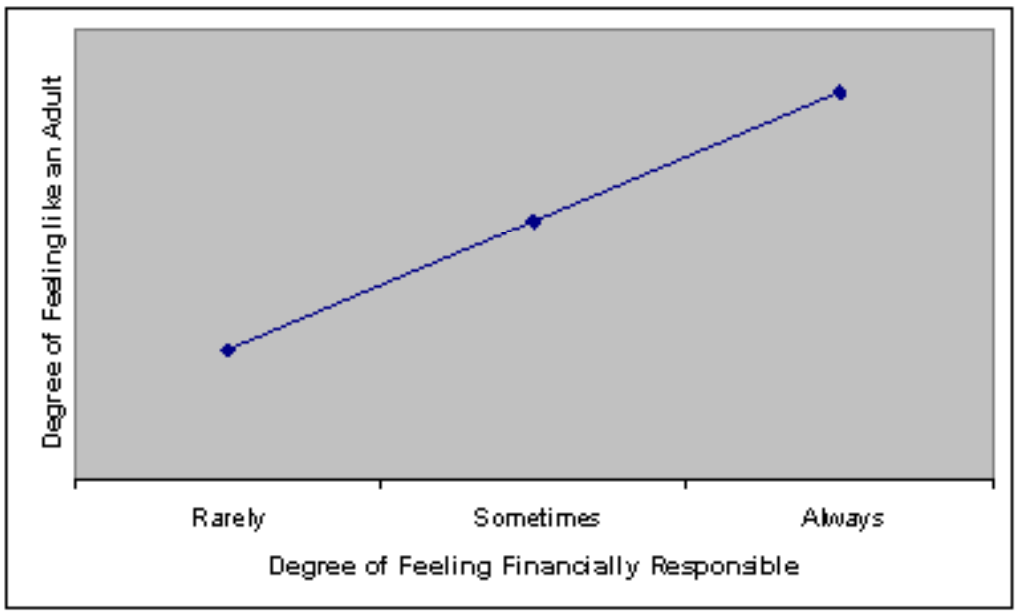

Figure 1: A Psychological Perspective of Attaining Self-Perceived Adult Status

her self to be an adult. Yet, the relationship between these perceptions and an individual's self reports of feeling like an adult is only beginning to be investigated.

Arnett (1998) did ask the respondents whether or not they thought that they had reached adulthood. The majority answered in the affirmative, but a large portion also remarked "in some respects yes, in some respects no" (304). He reasons that this is due to the long process of transitioning to adulthood. It takes time to develop adult maturity. This explanation, however, offers a limited understanding of the factors that lead youth to believe that they have personally reached adult status (cf. Shanahan, Porfeli, Mortimer, and Erickson 2005). In Arnett's studies, the respondents who were parents cited parenthood as a significant marker in their own transition into adulthood. Taking this information into account, it would seem that there are other factors than personal conceptions of adulthood that affect an individual's subjective age identity. These other factors have important implications. For example, since African Americans and Latinos statistically experience parenthood sooner than other race and ethnic populations, it is likely that they will have an older subjective age identity for different reasons than 
other teenagers and persons in their early twenties who have not experienced equivalent transitions. Women and men have traditionally been socialized to take on different responsibilities, such as child-care or paid-employment, which social roles are likely to affect their feelings of adult status, even if their conceptions of adulthood are the same. There are probably class differences as well, given that lower class members have less time to explore options for an education and a career due to their financial constraints. Moreover, there are most likely significant intersections of race, gender and class when accounting for feelings of adulthood.

\section{Sociology}

The second theoretical perspective considers these social characteristics by taking a sociological viewpoint of subjective age identity and the transition to adulthood. In a longitudinal study, Benson and Furstenberg, Jr. (2004) found that respondents who had experienced the transitions of leaving home, working and parenting at the second wave were more likely to consider themselves to be adults. This varied by parents' educational attainment and the structure of the family of origin. Individuals who were not raised with both biological parents or who had parents that did not obtain a college degree had better odds of feeling like an adult than individuals who experienced other social circumstances. The combination of certain social conditions was also important. Those who left home and found employment were more likely to consider themselves to be adults than those who found employment but were still living at home. Additionally, Benson and Furstenberg, Jr. discovered that individuals who experienced a reversal in particular transitions (e.g., returning to the home of origin) had increased odds of losing the feeling of being an adult. After controlling for the life course changes and historical conditions, none of the individualistic qualities that Arnett $(1998,2000,2003)$ identified as important were found to be significant in increasing the odds of feeling like an adult. Shanahan (2000a) documents some of the effects of social structure on the perceptions of young people. Social structures often determine educational quality and occupational potential, which 


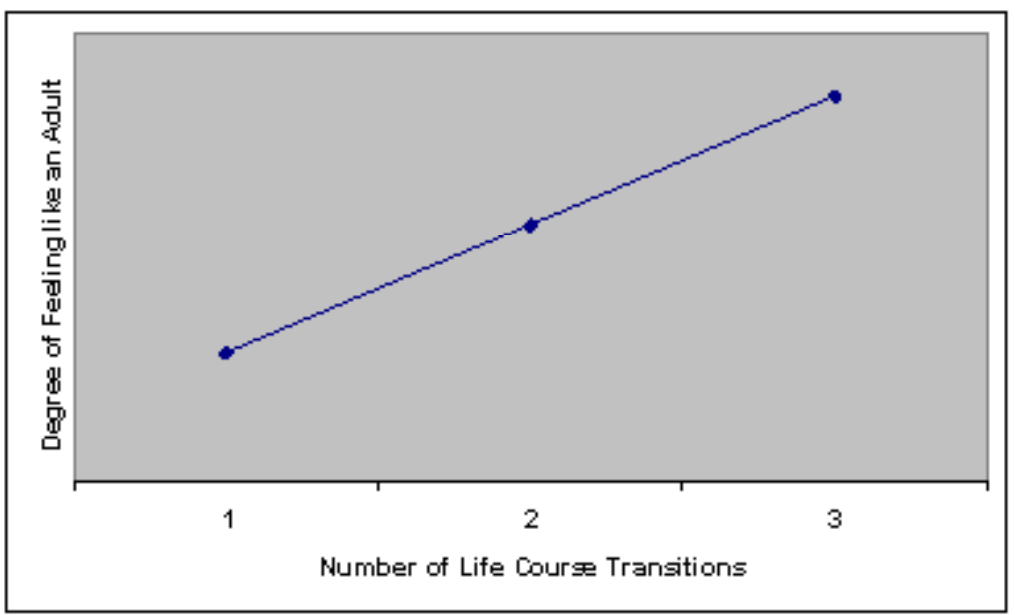

Figure 2: Life Course Transitions and Feeling like an Adult

in turn influence family stability and duration in poverty. All of these social conditions impact an individual's perception of age and adulthood and, consequently, a person's own subjective age identity. Figures 2 through 4 offer three simple bivariate illustrations of a sociological perspective.

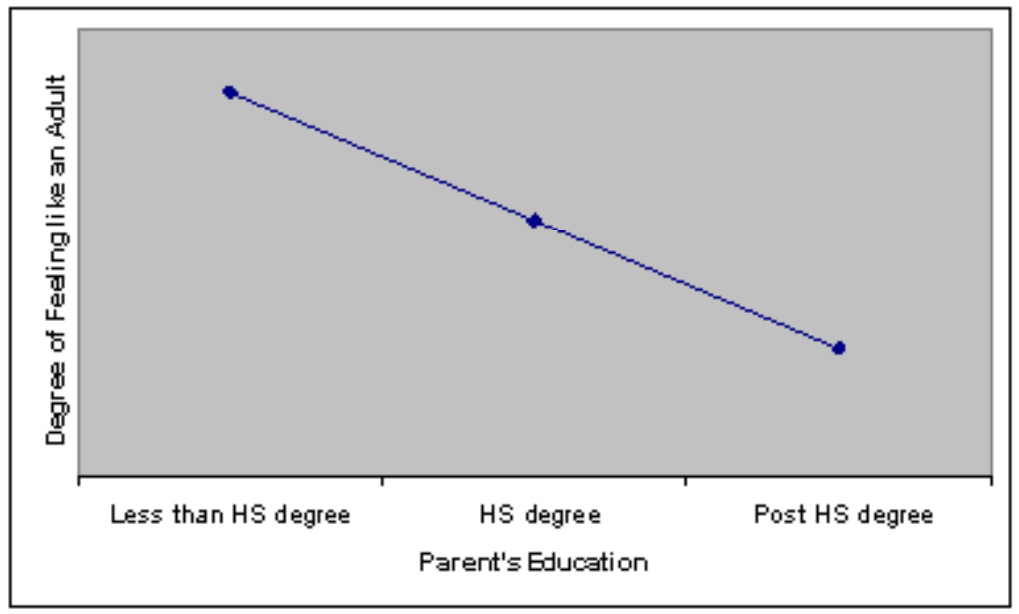

Figure 3: Parent's Education and Feeling like an Adult 


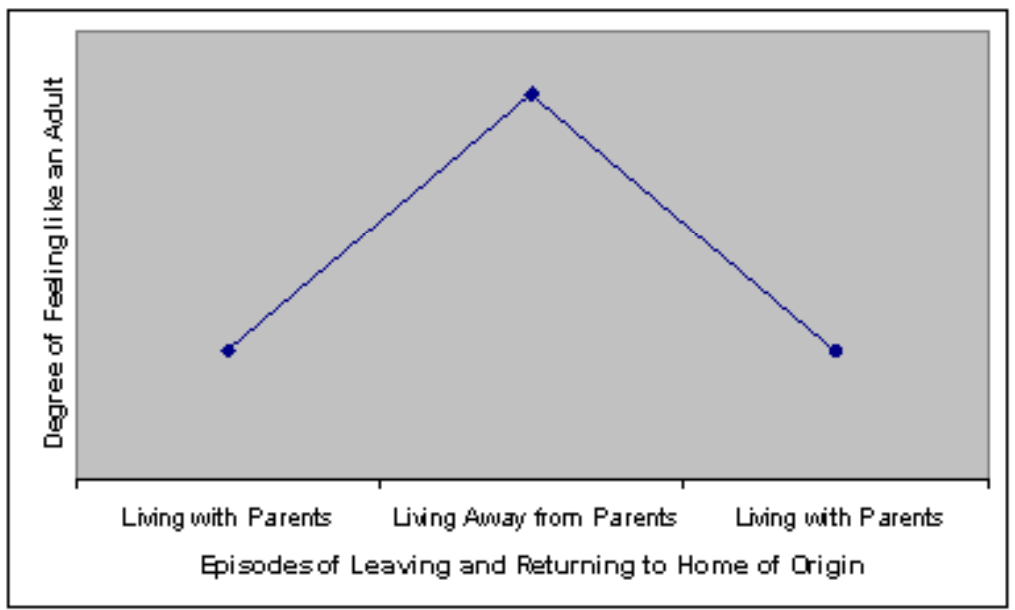

Figure 4: Residence at Parent's Home and Feeling like an Adult

While these graphs offer a visualization of the sociological perspective, they are only basic representations of more complex theoretical ideas. For example, the relationship in Figure 2 may indeed be positive and linear, but the different life course transitions may have unequal effects on feeling like an adult. Parenthood, for example, has already been shown to have a stronger effect than graduating high school or college in making people feel that they have become an adult. The relationship in Figure 3 may also be linear and negative. Yet, some evidence suggests that a mother's education may have a greater impact than a father's because she tends to be the parent who socializes the children. Or, parental education may depend on the gender of the parent and the gender of the child, same sex versus opposite sex. Lastly, in Figure 4, when a child returns home, his or her self-perceived adult status may not return to the exact level from when he or she left home in the beginning. 1 The person may not feel completely like an adult anymore, but at least closer to adulthood than before leaving home for the first time. It may be worthwhile for future research to examine these differences in more theoretical and empirical detail. 
A third perspective combines both psychological and sociological perspectives to explain the outcome of feeling like an adult. Shanahan, Porfeli, Mortimer, and Erickson (2005) suggest that there is a confluence of individual qualities and adult social roles in the make-up of a person's subjective age identity. From their study of 1,010 youth in St. Paul, Minnesota, they find three outcomes: Feelings of adulthood differ by social domain (e.g. with friends, with parents, at work, at school); family transitions, such as leaving the home of origin, marrying, and having children, increase the likelihood that a person will report feeling like an adult; and some individual qualities, such as feeling financially responsible, also impact an individual's self-perceived adult status. Due to data limitations, however, they were unable to examine interactions between individualistic qualities and family transitions, which would further test the idea of a confluence of psychological and sociological factors. Yet, they suggest that there is tentative support for such a model. In a qualitative study, Scheer and Palkovitz (1994) also suggest that both social status markers and cognitive factors influence the transition to adulthood. The majority of their sample, which had an average age of 21.6, described in interviews that a combination of events (e.g., leaving the parental home) and personal characteristics (e.g., ability to make own decisions) influenced their perceptions of self-perceived adult status.

\section{Theoretical Considerations}

Each of the three theoretical perspectives offer significant ways to examine the development of subjective age identity, especially as it relates to the notion of transitioning to adulthood. While combining psychological and sociological concepts seems theoretically intuitive, future research should continue to test the relative explanatory strength of each position. It may be that psychological dynamics are a function of social experiences or it may be that particular social experiences are a result of personality 
traits or unfettered individual conceptions. Or, indeed, both may be interrelated as Shanahan and colleagues (2005) suggest.

One area that needs a greater amount of exploration in each of these three theoretical frameworks is the idea of processes. For example, with the psychological perspective, what exactly are the mechanisms that lead to feelings of financial responsibility? Is it a mental desire to boost one's self-esteem by viewing the self positively in contrast to others who have less individual wealth or is it the cognitive development of associating money with adult status? With the sociological perspective, is the significant impact of having a child due to interpersonal relations with family and friends who suddenly treat the new parent in a more mature manner, leading to feelings of adulthood, or is it due to institutions that constrain a new parent to take certain actions, such as leave school or work, as well as influence changes in a person's perceptions of group membership (e.g., from youth to adult)? Further consideration of the processes involved in subjective age identity and the transition to adulthood would strengthen the theoretical explanations.

\section{Methodological Considerations}

At this point in the study of subjective age identity during the transition to adulthood, there are also methodological considerations. First, most research has used cross-sectional data (for an exception, see Benson and Furstenberg, Jr. 2004), even though one characteristic of subjective age identity is that it changes over time. Panel designs of subjective age identity will be better able to evaluate the causal ordering of various psychological and sociological concepts. Additionally, in-depth interviews may help researchers to identify potential processes that result in a particular subjective age identity. Then in experimental settings some of the mechanisms could be teased out as important or unimportant. For example, one experimental design may involve a subject and confederate playing a game. At some point during the game, the subject could be made to hypothetically have a child. Throughout the rest of the game, the confederate could show deference to the 
subject by asking questions about what it is like to have a child. In the control group, the subject plays the game alone. Afterward, will there be a significant difference in self-perceived adult status between the two groups?

Second, most studies have operationalized subjective age identity with categorical variables. For example, Shanahan, Porfeli, Mortimer, and Erickson (2005) use a variable that asks respondents if they feel entirely like an adult, somewhat like an adult, or not at all like an adult in various situations, such as at work or at school. This lends itself to certain statistical techniques, such as logistic regression, that may not be able to offer as much explanatory value as other methods, such as OLS regression. That is, it is arguably easier to interpret the $\mathrm{R}^{2}$ of OLS than the pseudo- $\mathrm{R}^{2}$ of logistic regression. Operationalizing self-perceived adult status in a way that more closely resembles an interval-level measure may be helpful. For instance, a question may ask respondents: In a typical week, how many days do you feel like an adult with 0 days being the minimum and 7 days being the maximum? In order to capture social domains, perhaps a question could ask: In terms of percentages, with 0 percent being the minimum and 100 percent being the maximum, what percentage of the time do you feel like an adult at [e.g., home, school, work, with parents, with friends, with children, etc.]?

Third, since prior research has shown that individuals perceive their adult status differently in different social domains, it seems worthwhile to explore the impact of interviewer effects. The idea is that individuals may judge their age differently when they are interacting with people who are their own age (e.g., at school), who are older (e.g., at home), or who may have a different social status than them (e.g., at work). Consequently, if the survey is conducted in-person or over the telephone, the interviewer's perceived age and social status (e.g., gender) may affect the respondent's answers. There may also be differences by survey mode. Mail surveys may generate significantly different answers than in-person interviews or telephone surveys because of the difference in social pressure to answer questions in a certain way. 


\section{Conclusion}

Subjective age identity during the transition to adulthood is a complex social phenomenon. Researchers who take a psychological perspective find individualistic qualities to be important in explaining a person's feelings of adulthood, while researchers who take a sociological perspective find social context and social roles to be paramount. More recently, a third group of researchers are attempting to combine concepts from both disciplines to account for self-perceived adult status. Each of the three theoretical frameworks will benefit from a clearer understanding of the processes involved in developing a subjective age identity, as well as incorporating different methodological techniques, from longitudinal surveys and laboratory experiments to defining continuous variables. Gaining such knowledge has implications for individuals and social service workers who want to understand behavior for applied reasons, as well as implications for scholars who want to understand other social phenomenon, such as psychological well-being, physical health, and the timing of various life course transitions (Kaufman and Elder 2003; Logan et al. 1992; Montepare and Lachman 1989; Neugarten 1997).

\section{References}

Arnett, Jeffrey Jensen. 1998. "Learning to Stand Alone: The Contemporary American Transition to Adulthood in Cultural and Historical Context." Human Development 41:295-315

. 2000."Emerging Adulthood: A Theory of Development from the Late Teens through the Twenties." American Psychologist. May: 469-480.

_ 2003. "Conceptions of the Transition to Adulthood Among Emerging Adults in American Ethnic Groups." Pp. 63-75 in Exploring Cultural Conceptions of the Transition to Adulthood, edited by Jeffrey Jensen Arnett and Nancy L. Galambos. San Francisco: Jossey-Bass.

Arnett, Jeffrey Jensen, and Susan Taber. 1994. "Adolescence Terminable and Interminable: When Does Adolescence End?” Journal of Youth and Adolescence 23:517-537.

Barak, Benny. 1987. “Cognitive Age: A New Multidimensional Approach 
to Measuring Age Identity." International Journal on Aging and Human Development 25:109-128.

Barnes-Farrell, Janet L., and Michael J. Piotrowski. 1989. "Workers' Perceptions of Discrepancies between Chronological Age and Personal Age: You're Only as Old as You Feel." Psychology and Aging 4:376-377.

Benson, Janel, and Frank Furstenberg, Jr. 2004. "Subjective Perceptions of Adulthood among Urban Youth: Are Demographic Transitions Still Relevant?" Paper prepared for the Annual Meetings of the Population Association of America, Boston, MA, April 2, 2004.

Blau, Zena S. 1956. "Changes in Status and Age Identification." American Sociological Review 21:198-203.

Fussell, Elizabeth, and Frank F. Furstenberg, Jr. 2005. "The Transition to Adulthood during the Twentieth Century: Race, Nativity, and Gender." Pp. 29-75 in On the Frontier of Adulthood: Theory, Research, and Public Policy, edited by Richard A. Settersten, Jr., Frank F. Furstenberg, Jr., and Ruben G. Rumbaut. Chicago: University of Chicago Press.

Goldsmith, Ronald E., and Richard A. Heiens. 1992. "Subjective Age: A Test of Five Hypotheses." The Gerontologist 32:312-317.

Greene, A.L. 1990. "Great Expectations: Constructions of the Life Course during Adolescence." Journal of Youth and Adolescence 19:289306.

Greene, A.L., Susan M. Wheatley, and John F. Aldava IV. 1992. "Stages on Life's Way: Adolescents' Implicit Theories on the Life Course." Journal of Adolescent Research 7:364-381.

Hogan, Dennis P. 1978. "The Variable Order of Events in the Life Course." American Sociological Review 43:573-586.

—. 1981. Transitions and Social Change: The Early Lives of American Men. New York: Academic

Hogan, Dennis P., and Nan Marie Astone. 1986. "The Transition to Adulthood." Annual Review of Sociology 12:109-130.

Hubley, Anita M., and David F. Hultsch. 1994. "The Relationship of Personality Trait Variables to Subjective Age Identity in Older Adults." Research on Aging 16:415-439.

Hubley, Anita M., and David F. Hultsch. 1996. "Subjective Age and Traits." Research on Aging 18:494-496.

Kastenbaum, Robert, Valerie Derbin, Paul Sabatini, and Steven Artt. 1972. “"The Ages of Me': Toward Personal and Interpersonal Definitions of Functional Aging." Aging and Human Development 3:197-211. 
Kaufman, Gayle, and Glen H. Elder, Jr. 2002. "Revisiting Age Identity: A Research Note." Journal of Aging Studies 16:169-176.

—. 2003. "Grandparenting and Age Identity." Journal of Aging Studies 17:269-282.

Logan, John R., Russell Ward, and Glenna Spitze. 1992. "As Old As You Feel: Age Identity in Middle and Later Life." Social Forces 71:451-467.

Marini, Margaret Mooney. 1984a. "The Order of Events in the Transition to Adulthood." Sociology of Education 57:63-84.

—. 1984b. "Age and Sequencing Norms in the Transition to Adulthood." Social Forces 63:229-244.

Montepare, Joann M. 1991. "Characteristics and Psychological Correlates of Young Adult Men's and Women's Subjective Age." Sex Roles 24:323-333.

Montepare, Joann M., and Margie E. Lachman. 1989. “'You're Only as Old as You Feel': Self-Perceptions of Age, Fears of Aging, and Life Satisfaction from Adolescence to Old Age." Psychology and Aging 4:73-78.

Mortimer, Jeylan T. 2000. “Adulthood." Pp. 78-86 in Encyclopedia of Sociology, $2^{\text {nd }}$ Edition, edited by Edgar I. Borgatia and Rhonda J.V. Montgomery. New York: Macmillan Reference USA.

Mouw, Ted. 2005. "Sequences of Early Adult Transitions: A Look at Variability and Consequences." Pp. 256-291 in On the Frontier of Adulthood: Theory, Research, and Public Policy, edited by Richard A. Settersten, Jr., Frank F. Furstenberg, Jr., and Ruben G. Rumbaut. Chicago: University of Chicago Press.

Neugarten, Bernice L., Joan W. Moore, and John C. Lowe. 1965. "Age Norms, Age Constraints, and Adult Socialization." American Journal of Sociology 70:710-717.

_ 1997. The Meaning of Age: Selected Papers of Bernice L. Neugarten. Chicago: University of Chicago Press.

Riley, Matilda White, Anne Foner, and Joan Waring. 1988. "Sociology of Age." Pp. 243-290 in Handbook of Sociology, edited by Neil J. Smelser. Newbury Park, CA: Sage Publications.

Scheer, Scott D., and Rob Palkovitz. 1994. "Adolescent-to-Adult Transitions: Social Status and Cognitive Factors." Sociological Studies of Children 6:125-140.

Settersten, Jr., Richard A. 2003. "Age Structuring and the Rhythm of the Life Course." Pp. 81-93 in Handbook of the Life Course, ed. Jeylan T. Mortimer and Michael J. Shanahan. New York: Kluwer Academic 
Settersten, Jr., Richard A., and Gunhild O. Hagestad. 1996. "What's the Latest? Cultural Age Deadlines for Family Transitions." The Gerontologist 36:178-188.

Settersten, Jr., Richard A., and Karl Ulrich Mayer. 1997. "The Measurement of Age, Age Structuring, and the Life Course." Annual Review of Sociology 23:233-261.

Shanahan, Michael J. 2000a. "Pathways to Adulthood in Changing Societies: Variability and Mechanisms in Life Course Perspective." Annual Review of Sociology 26:667-692.

2000b. "Adolescence." Pp. 1-18 in Encyclopedia of Sociology, $2^{\text {nd }}$ Edition, edited by Edgar I. Borgatia and Rhonda J.V. Montgomery. New York: Macmillan Reference USA.

Shanahan, Michael J., Erik J. Porfeli, Jeylan T. Mortimer, and Lance D. Erickson. 2005. "Subjective Age Identity and the Transition to Adulthood: When Adolescents Become Adults?" Pp. 225-255 in On the Frontier of Adulthood: Theory, Research, and Public Policy, edited by Richard A. Settersten, Jr., Frank F. Furstenberg, Jr., and Ruben G. Rumbaut. Chicago: University of Chicago Press.

Tilton-Weaver, Lauree C., Erin T. Vitunski and Nancy L. Galambos. 2001. "Five Images of Maturity in Adolescence: What Does 'Grown Up' Mean?" Journal of Adolescence 24:143-158.

Zola, Iriving K. 1962. "Feelings about Age among Older People.” Journal of Gerontology 17:65-68. 